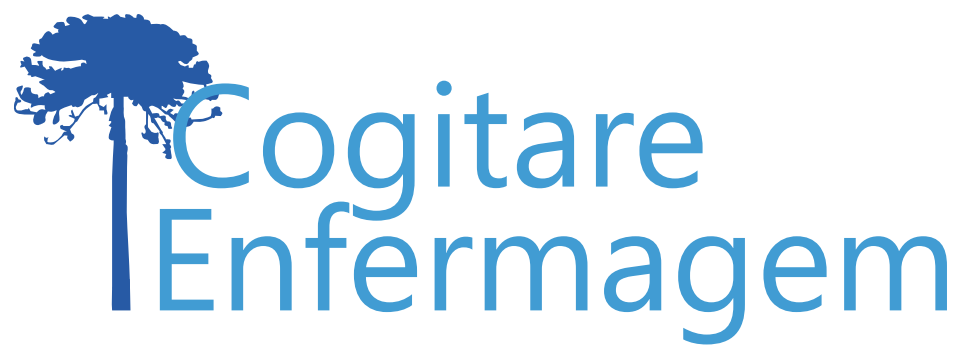

\title{
VIOLÊNCIA INTERPESSOAL E AUTOPROVOCADA: CARACTERIZAÇÃO DOS CASOS NOTIFICADOS EM UMA REGIONAL DE SAÚDE DO PARANÁ
}

Cinthia Mara de Andrade1, Géssica Tuani Teixeira², Thaisa Borges França ${ }^{3}$, Márcio Rambo ${ }^{4}$ Marcela Gonçalves Trevisan ${ }^{5}$, Edinara Casaril ${ }^{6}$, Lediana Dalla Costa ${ }^{7}$

\section{RESUMO}

Objetivo: caracterizar os casos de violência interpessoal e autoprovocada por meio de notificações de uma Regional de Saúde do interior do Paraná.

Método: pesquisa documental, retrospectiva, de abordagem quantitativa, realizada entre maio e junho de 2018. Oestudo analisou as notificações de violência interpessoal e autoprovocada ocorridas entre 2013 e 2016. Os dados foram submetidos à análise estatística descritiva, apresentados por distribuição de frequências absolutas e relativas.

Resultados: Evidenciou-se aumento da violência. Foram registrados 766 casos, com predomínio de vítimas do sexo feminino em 565 (73,8\%) notificações. Destas, $322(42 \%)$ eram adultas e 277 $(47,9 \%)$ possuíam companheiro. Em relação aos agressores, 548 (75,5\%) eram homens e 393 $(51,3 \%)$ adultos.

Conclusão: A pesquisa confirma a importância das notificações e de uma assistência à saúde pautada na responsabilidade dos profissionais. O crescente aumento da violência torna essencial a implementação de políticas públicas e treinamento dos profissionais responsáveis pelas notificações.

DESCRITORES: Violência; Saúde Pública; Indicadores de Morbimortalidade; Agressão; Política pública.

\section{COMO REFERENCIAR ESTE ARTIGO:}

Andrade CM de, Teixeira GT, França TB, Rambo M, Trevisan MG, Casaril E, et al. Violência interpessoal e autoprovocada: caracterização dos casos notificados em uma regional de saúde do Paraná. Cogitare enferm. [Internet]. 2020 [acesso em "colocar data de acesso, dia, mês abreviado e ano"]; 25. Disponível em: http:// dx.doi.org/10.5380/ce.v25i0.63758.

Este obra está licenciado com uma Licença Creative Commons Atribuição 4.0 Internacional.

${ }^{1}$ Enfermeira. Universidade Paranaense. Francisco Beltrão, PR, Brasil. (ㄱ

${ }^{2}$ Enfermeira. Especialista em Saúde Pública com Ênfase na Atenção à Saúde da Mulher. Docente de Enfermagem da Universidade Paranaense. Francisco Beltrão, PR, Brasil. $\odot$

${ }^{3}$ Discente de Enfermagem. Universidade Paranaense. Francisco Beltrão, PR, Brasil. $\odot$

${ }^{4}$ Discente de Ciências Econômicas. Universidade Estadual do Oeste do Paraná. Francisco Beltrão, PR, Brasil.

${ }^{5}$ Enfermeira. Especialista em Saúde Pública com Ênfase na Atenção à Saúde da Mulher. Responsável Técnica de Graduação em Enfermagem da Universidade Paranaense. Francisco Beltrão, PR, Brasil. $\odot$

${ }^{6}$ Enfermeira. $8^{\circ}$ Regional de Saúde da Secretaria Estadual da Saúde do Paraná. Francisco Beltrão, PR, Brasil. $\left(\frac{1}{}\right.$

${ }^{7}$ Enfermeira. Mestre em Saúde e Gestão do Trabalho. Docente de Enfermagem da Universidade Paranaense. Francisco Beltrão, PR, Brasil. 


\title{
INTERPERSONAL AND SELF-DIRECTED VIOLENCE: CHARACTERIZATION OF CASES REPORTED IN A REGIONAL HEALTH DEPARTMENT OF PARANÁ
}

\begin{abstract}
Objective: to characterize cases of interpersonal and self-directed violence through reports from a Regional Health Department in the interior of Paraná.

Method: retrospective documentary research, with a quantitative approach, carried out between May and June 2018. The study analyzed the reports of interpersonal and self-harm that took place between 2013 and 2016. The data were submitted to descriptive statistical analysis, presented by absolute and relative frequency distribution.

Results: There was an increase in violence. A total of 766 cases were reported, with a predominance of female victims in $565(73.8 \%)$ reports. Of these, $322(42 \%)$ were adults and $277(47.9 \%)$ had a partner. Regarding the aggressors, 548 (75.5\%) were men and 393 (51.3\%) adults.

Conclusion: The research reinforces the importance of reporting and health care based on the responsibility of professionals. The increase in violence makes it essential to implement public policies and train professionals focused on reporting.
\end{abstract}

DESCRIPTORS: Violence; Public Health; Indicators of Morbidity and Mortality; Aggression; Public Policy.

\section{VIOLENCIA INTERPERSONAL Y AUTOINFLIGIDA: CARACTERIZACIÓN DE LOS CASOS NOTIFICADOS EN UNA REGIONAL DE SALUD DE PARANÁ}

\section{RESUMEN:}

Objetivo: caracterizar los casos de violencia interpersonal y autoinfligida por medio de notificaciones de una Regional de Salud de interior de Paraná.

Método: investigación documental, retrospectiva, de abordaje cuantitativo, que se realizó entre mayo y junio de 2018. El estudio ha analizado las notificaciones de violencia interpersonal y autoinfligida que ocurrieron entre 2013 y 2016. Se sometieron los datos al análisis estadístico descriptivo, y se los presentaron por distribución de frecuencias absolutas y relativas.

Resultados: Se constató aumento de violencia. Se registraron 766 casos, con mayoría de víctimas del sexo femenino en 565 (73,8\%) notificaciones. De estas, $322(42 \%)$ eran adultas y $277(47,9 \%)$ tenían pareja. Acerca de los agresores, 548 (75,5\%) eran hombres y 393 (51,3\%) adultos.

Conclusión: La investigación confirma la importancia de las notificaciones y de una asistencia a la salud pautada en la responsabilidad de los profesionales. El creciente aumento de la violencia hace esencial la implementación de políticas públicas y entrenamiento de los profesionales responsables por las notificaciones.

DESCRIPTORES: Violencia; Salud Pública; Indicadores de Morbimortalidad; Agresión; Política pública. 
Para a Organização Mundial da Saúde (OMS), o termo violência define-se como o uso intencional de força física, real ou em ameaça, contra si próprio, outro indivíduo, grupo ou comunidade, podendo resultar em lesão, dano psicológico e morte(1). Atualmente, é considerada um problema de saúde pública por ser uma das principais causas de morbimortalidade no mundo, resultando em diversos impactos que afetam tanto o indivíduo quanto a população(2).

De acordo com a Classificação Internacional de Doenças (CID), além dos acidentes e outras lesões, as agressões autoprovocadas de maneira voluntária também são consideradas causas externas. Em 2014, no cenário brasileiro, por meio de um estudo de reflexão, observou-se que dos 1.222.381 óbitos, 155.610 foram associados a causas externas. A violência alcança diversos níveis de cidadania, na medida em que atinge diferentes raças, faixas etárias e sexo(3).

É válido salientar que as agressões representam 37,4\% dos óbitos, ao passo que as causas externas retratam a terceira causa de morte na população geral e a primeira na faixa etária de até 49 anos. Assim, ao considerar a representatividade deste problema, - Ministério da Saúde (MS) elaborou a Política de Redução de Morbimortalidade por Acidentes e Violência, regulamentada pela Portaria MS/GM nº 737 de 16 de maio de 2001, aprovada pela Comissão Intergestores Tripartite (CIT) através da Resolução n 309 de 8 de março de $2001^{(4)}$.

Ademais, o MS desenvolveu um sistema de notificações, tornando-as obrigatórias em casos de violência ou suspeita, propiciando o desenvolvimento de políticas públicas para a proteção das vítimas, bem como o conhecimento epidemiológico dos casos notificados, permitindo identificar os grupos mais vulneráveis e auxiliar na criação de ações de prevenção e proteção às vítimas ${ }^{(5)}$.

Este estudo torna-se relevante ao enfatizar o perfil epidemiológico da violência, e ao identificar a principal faixa etária acometida, o sexo do provável autor e da vítima desta agressão. Portanto, a presente pesquisa objetivou caracterizar os casos de violência interpessoal e autoprovocada por meio de notificações ocorridas em uma Regional de Saúde do interior do Paraná.

\section{MÉTODO}

Trata-se de pesquisa documental e retrospectiva, de abordagem quantitativa, com o propósito de caracterizar os casos de violência notificados no Sistema de Informação de Agravos de Notificação (SINAN) da $8^{a}$ Regional de Saúde. Essa regional abrange 27 municípios, de acordo com o último censo do Instituto Brasileiro de Geografia e Estatística (IBGE) compreendendo uma população de aproximadamente 324.178 habitantes ${ }^{(6)}$.

A amostra da pesquisa corresponde às notificações de violência interpessoal e autoprovocada, que foram registradas durante o levantamento histórico realizado entre os períodos de janeiro de 2013 e dezembro de 2016.

Foram incluídas na pesquisa todas as notificações de violência interpessoal e autoprovocada registradas no período do levantamento histórico. Como critérios de exclusão, destacam-se as fichas de notificações com preenchimento incompleto, totalizando 25 notificações.

A coleta de dados realizou-se entre maio e junho de 2018, elegendo as variáveis: sexo, faixa etária, raça/cor, escolaridade, situação conjugal, orientação sexual, local de ocorrência, ano da notificação, unidade notificadora, classificação, tipologia e número 
de violências, sexo e ciclo de vida do agressor, número de envolvidos, tipo da violência, meio de agressão, suspeita de uso de álcool pelo agressor, vínculo entre vítima e autor, se ocorreu outras vezes, e profilaxia em caso de violência sexual.

Como referencial teórico metodológico, utilizaram-se manuais, protocolos, legislações e publicações científicas que abordaram a temática proposta entre os anos de 2013 e 2018.

Os dados foram tabulados no Excel e receberam tratamento no programa Statistical Package for the Social Sciences (SPSS) versão 25.0. A estatística descritiva foi utilizada para caracterizar a amostra e distribuição das frequências.

Este estudo foi aprovado pelo Comitê de Ética em Pesquisa Envolvendo Seres Humanos de uma Universidade Paranaense, sob o parecer 2.613.730.

\section{RESULTADOS}

Entre os anos de 2013 e 2016, foram registrados 766 casos de violência. Levando em consideração as características sociodemográficas, foi possível observar maior incidência de casos na população feminina 565 (73,8\%). Quanto à faixa etária, houve destaque para adultos $322(42 \%)$ e adolescentes 180 (23,5\%). A raça predominante foi branca $583(76,1 \%)$, e referente à escolaridade da vítima, $327(42,7 \%)$ possuíam menos que oito anos de estudo.

$\mathrm{Na}$ variável situação conjugal, houve destaque para vítimas com companheiro 277 $(47,9 \%)$ e na variável orientação sexual, heterossexuais $492(64,2 \%)$, e no que tange ao local de ocorrência, vale destacar que a residência obteve um índice de $546(71,3 \%)$, seguido de via pública 79 (10,3\%) (Tabela 1).

Tabela 1 - Dados sociodemográficos das vítimas de violência interpessoal e autoprovocada, notificadas em uma Regional de Saúde. Francisco Beltrão, PR, Brasil, 2016 (continua)

Variável

\begin{tabular}{lcc} 
& Absoluta (n) & Relativa (\%) \\
\hline Sexo & & \\
\hline Feminino & 565 & 73,8 \\
\hline Masculino & 201 & 26,2 \\
\hline Faixa etária & & \\
\hline Criança (<12 anos) & 99 & 12,9 \\
\hline Adolescente (12 a 18 anos) & 180 & 23,5 \\
\hline Jovem (19 a 24 anos) & 106 & 13,8 \\
\hline Adulto (25 a 59 anos) & 322 & 42 \\
\hline Idoso (igual $>60$ anos) & 59 & 7,8 \\
\hline Raça/cor & & \\
\hline Branca & 583 & 76,1 \\
\hline Preta & 15 & 2 \\
\hline Amarela & 3 & 0,4 \\
\hline Parda & 157 & 20,5 \\
\hline
\end{tabular}




\begin{tabular}{|c|c|c|}
\hline Indígena & 1 & 0,1 \\
\hline Ignorada & 7 & 0,9 \\
\hline \multicolumn{3}{|l|}{ Escolaridade } \\
\hline Menor que 8 anos de estudo & 327 & 42,7 \\
\hline Maior que 8 anos de estudo & 302 & 39,4 \\
\hline Não se aplica & 40 & 5,2 \\
\hline Ignorado & 97 & 12,7 \\
\hline \multicolumn{3}{|l|}{ Situação Conjugal } \\
\hline Com companheiro & 277 & 47,9 \\
\hline Sem companheiro & 367 & 36,2 \\
\hline Não se aplica & 90 & 11,7 \\
\hline Ignorado & 32 & 4,2 \\
\hline \multicolumn{3}{|l|}{ Orientação sexual } \\
\hline Heterossexual & 492 & 64,2 \\
\hline Homossexual & 10 & 1,3 \\
\hline Bissexual & 3 & 0,4 \\
\hline Não se aplica & 133 & 17,4 \\
\hline Ignorado & 128 & 16,7 \\
\hline \multicolumn{3}{|l|}{ Local de ocorrência } \\
\hline Residência & 546 & 71,3 \\
\hline Via pública & 79 & 10,3 \\
\hline Habitação coletiva & 5 & 0,7 \\
\hline Escola & 20 & 2,6 \\
\hline Local de prática esportiva & 2 & 0,3 \\
\hline Bar ou similar & 41 & 5,4 \\
\hline Comércio/Serviços & 5 & 0,6 \\
\hline Indústrias/Construção & 4 & 0,5 \\
\hline Outro & 55 & 7,1 \\
\hline Ignorado & 9 & 1,2 \\
\hline
\end{tabular}

Dentre as características do evento, constatou-se o comportamento crescente das notificações. Referente à unidade notificadora, a de saúde foi a que mais notificou $763(99,7 \%)$. Quanto à classificação da violência, 628 (82\%) dos casos foram de violência interpessoal e 138 (18\%), de violência autoprovocada.

No que se refere à tipologia da violência, 313 (40,9\%) dos casos notificados foram contra mulheres e $279(36,4 \%)$ contra crianças e adolescentes. Já em relação ao número de violências, $425(55,5 \%)$ das vítimas sofreram um tipo, enquanto $240(31,3 \%)$ sofreram dois, simultaneamente. Referente ao ciclo de vida do agressor, houve predomínio de adultos $393(51,3 \%)$, e quanto ao sexo, predominou o masculino $578(75,5 \%)$. Levando em consideração o número de envolvidos no ato violento, 555 (72,5\%) compreendiam apenas uma pessoa (Tabela 2). 
Tabela 2 - Casos de notificação de violência interpessoal e autoprovocada em uma Regional de Saúde. Francisco Beltrão, PR, Brasil, 2016 (continua)

Variável

\begin{tabular}{|c|c|c|}
\hline & Absoluta (n) & Relativa (\%) \\
\hline \multicolumn{3}{|l|}{ Ano da notificação } \\
\hline 2013 & 75 & 9,8 \\
\hline 2014 & 135 & 17,6 \\
\hline 2015 & 179 & 23,4 \\
\hline 2016 & 377 & 49,2 \\
\hline \multicolumn{3}{|l|}{ Unidade Notificadora } \\
\hline Unidade de saúde & 763 & 99,7 \\
\hline Unidade de assistência social & 1 & 0,1 \\
\hline Centro de atendimento à mulher & 1 & 0,1 \\
\hline Ignorado & 1 & 0,1 \\
\hline \multicolumn{3}{|l|}{ Classificação da violência } \\
\hline Interpessoal & 628 & 82 \\
\hline Autoprovocada & 138 & 18 \\
\hline \multicolumn{3}{|l|}{ Tipologia da violência } \\
\hline Crianças e adolescentes & 279 & 36,4 \\
\hline Mulheres & 313 & 40,9 \\
\hline Homens & 115 & 15 \\
\hline Idosos & 59 & 7,7 \\
\hline \multicolumn{3}{|l|}{ Número de violências } \\
\hline Um & 425 & 55,5 \\
\hline Dois & 240 & 31,3 \\
\hline Três & 67 & 8,7 \\
\hline Quatro & 28 & 3,7 \\
\hline Cinco & 6 & 0,8 \\
\hline \multicolumn{3}{|l|}{ Sexo do agressor } \\
\hline Feminino & 137 & 17,8 \\
\hline Masculino & 578 & 75,5 \\
\hline Ambos os sexos & 26 & 3,4 \\
\hline Ignorado & 25 & 3,3 \\
\hline \multicolumn{3}{|l|}{ Ciclo de vida do autor } \\
\hline Criança (0 a 9 anos) & 6 & 0,8 \\
\hline Adolescente (10 a 19 anos) & 68 & 8,9 \\
\hline Jovem (20 a 24 anos) & 90 & 11,6 \\
\hline Adulto (35 a 59 anos) & 393 & 51,3 \\
\hline Idoso (60 ou mais) & 15 & 2 \\
\hline Ignorado & 194 & 25,4 \\
\hline
\end{tabular}




\begin{tabular}{lcc}
\hline Número de envolvidos & & \\
\hline Um & 555 & 72,5 \\
\hline Dois ou mais & 180 & 23,5 \\
\hline Ignorado & 31 & 4
\end{tabular}

Quanto ao tipo de violência, houve predomínio da violência física, seguida da psicológica, 573 (74,8\%) e 304 (39,7\%), respectivamente. No que diz respeito às formas de agressão, evidenciou-se que a força corporal se destacou, 429 (56\%), seguida de ameaça 146 (19,1\%). Observou-se que, em 585 (50,3\%) casos, os agressores não tinham suspeita de uso de álcool, e no que se refere ao vínculo da vítima com o autor da violência, destacouse o cônjuge $152(19,8 \%)$ e o conhecido $132(17,2 \%)$. Dos casos notificados $343(44,8 \%)$, ocorreram mais de uma vez (Tabela 3 ).

Tabela 3 - Características do evento e vínculo do agressor com a vítima das notificações de violência interpessoal e autoprovocada em uma Regional de Saúde. Francisco Beltrão, PR, Brasil, 2016 (continua)

\begin{tabular}{lccc} 
Variável & $\begin{array}{c}\text { Sim } \\
\mathbf{n}(\%)\end{array}$ & $\begin{array}{c}\text { Não } \\
\mathbf{n}(\%)\end{array}$ & $\begin{array}{c}\text { Ignorado } \\
\mathbf{n}(\%)\end{array}$ \\
\hline Tipos de violência & & & \\
\hline Física & $573(74,8)$ & $198(25,2)$ & - \\
\hline Psicológica & $304(39,7)$ & $462(60,3)$ & - \\
\hline Tortura & $67(8,7)$ & $699(91,3)$ & - \\
\hline Sexual & $183(23,9)$ & $583(76,1)$ & - \\
\hline Financeira & $15(2)$ & $751(98)$ & - \\
\hline Negligência & $30(3,9)$ & $736(96,1)$ & - \\
\hline Trabalho infantil & $6(0,8)$ & $760(99,2)$ & - \\
\hline Intervenção legal & $5(0,7)$ & $761(99,3)$ & - \\
\hline Outro & $65(8,5)$ & $701(91,5)$ & - \\
\hline Meio de agressão & & & \\
\hline Força corporal & $429(56)$ & $330(43,1)$ & $7(0,9)$ \\
\hline Enforcamento & $54(7,1)$ & $704(91,9)$ & $8(1)$ \\
\hline Objeto contundente & $49(6,4)$ & $709(92,6)$ & $8(1)$ \\
\hline Corte & $103(13,5)$ & $656(85,6)$ & $7(0,9)$ \\
\hline Substância/objeto quente & $5(0,7)$ & $754(98,4)$ & $7(0,9)$ \\
\hline Envenenamento & $54(7,1)$ & $704(91,9)$ & $8(1)$ \\
\hline Arma de fogo & $30(3,9)$ & $729(95,2)$ & $7(0,9)$ \\
\hline Ameaça & $146(19,1)$ & $610(79,6)$ & $10(1,3)$ \\
\hline Outras agressões & $106(13,8)$ & $648(84,6)$ & $12(1,6)$ \\
\hline Suspeita do uso de álcool pelo agressor & $302(39,4)$ & $385(50,3)$ & $79(10,3)$ \\
\hline Vínculo com o provável autor da violência & & & \\
\hline & & & \\
\hline
\end{tabular}




\begin{tabular}{lccc}
\hline Pai & $35(4,6)$ & $721(94,1)$ & $10(1,3)$ \\
\hline Mãe & $23(3)$ & $734(95,8)$ & $9(1,2)$ \\
\hline Irmão & $27(3,5)$ & $730(95,3)$ & $9(1,2)$ \\
\hline Padrasto & $21(2,7)$ & $736(96,1)$ & $9(1,2)$ \\
\hline Madrasta & $3(0,4)$ & $705(92,0)$ & $58(7,6)$ \\
\hline Cônjuge & $152(19,8)$ & $605(79)$ & $9(1,2)$ \\
\hline Ex-cônjuge & $27(3,5)$ & $730(95,3)$ & $9(1,2)$ \\
\hline Namorado & $37(4,8)$ & $720(94,0)$ & $9(1,2)$ \\
\hline Ex-namorado & $13(1,7)$ & $744(97,1)$ & $9(1,2)$ \\
\hline Filho & $26(3,4)$ & $730(95,3)$ & $10(1,3)$ \\
\hline Desconhecido & $92(12)$ & $665(86,8)$ & $9(1,2)$ \\
\hline Conhecido & $132(17,2)$ & $626(81,8)$ & $8(1,0)$ \\
\hline Cuidador & $16(2,1)$ & $740(96,6)$ & $10(1,3)$ \\
\hline Patrão & $1(0,1)$ & $756(98,7)$ & $9(1,2)$ \\
\hline Relação institucional & $9(1,2)$ & $748(97,6)$ & $9(1,2)$ \\
\hline Policial & $3(0,4)$ & $752(98,2)$ & $11(1,4)$ \\
\hline Própria pessoa & $103(13,4)$ & $655(85,6)$ & $8(1)$ \\
\hline Outro tipo de relação & $71(9,3)$ & $682(89)$ & $13(1,7)$ \\
\hline Ocorreu outras vezes? & $343(44,8)$ & $378(49,3)$ & $45(5,9)$
\end{tabular}

Foi possível observar que, em caso de violência sexual, os procedimentos mais realizados foram profilaxia para o Vírus da Imunodeficiência Humana (HIV) 74 (9,7\%), profilaxia para Infecções Sexualmente Transmissíveis (IST) $63(8,3 \%)$ e coleta de sangue 48 $(6,4 \%)$ (Tabela 4).

Tabela 4 - Profilaxia em caso de violência sexual das notificações de violência interpessoal e autoprovocada em uma Regional de Saúde. Francisco Beltrão, PR, Brasil, 2016

\begin{tabular}{lccc} 
Variável & $\begin{array}{c}\text { Sim } \\
\mathbf{n}(\%)\end{array}$ & $\begin{array}{c}\text { Não } \\
\mathbf{n}(\%)\end{array}$ & $\begin{array}{c}\text { Ignorado } \\
\mathbf{n}(\%)\end{array}$ \\
\hline Profilaxia em caso de violência sexual & & & \\
\hline IST & $63(8,3)$ & $112(14,6)$ & $7(0,9)$ \\
\hline HIV & $74(9,7)$ & $101(13,2)$ & $7(0,9)$ \\
\hline Hepatite B & $27(3,6)$ & $147(19,2)$ & $8(1)$ \\
\hline Coleta de sangue & $48(6,4)$ & $126(16,4)$ & $8(1)$ \\
\hline Coleta de sêmen & $13(1,8)$ & $161(21)$ & $8(1)$ \\
\hline Coleta de secreção vaginal & $20(2,6)$ & $127(16,6)$ & $59(7,7)$ \\
\hline Contracepção de emergência & $43(5,6)$ & $104(13,6)$ & $59(7,7)$ \\
\hline Aborto previsto em lei & $1(0,1)$ & $127(16,6)$ & $59(7,7)$
\end{tabular}


Sabe-se que a violência se faz presente em toda a sociedade ao longo da história e atualmente configura-se como um problema mundial, causando grande impacto na qualidade de vida das vítimas, no que concerne tanto à saúde física quanto psicológica, bem como abalo familiar, absenteísmo no trabalho e na escola, dificultando a inserção e convívio social(4).

Em relação aos dados sociodemográficos, verificou-se maior prevalência de vítimas do sexo feminino, corroborando os dados publicados no Protocolo para o Atendimento às Pessoas em Situação de Violência Sexual(7), o qual revelou que o Paraná notificou, entre os anos de 2010 e 2016, 103.707 casos de violência sexual, doméstica e outras formas, com predomínio de vítimas do sexo feminino $(65,4 \%)$.

A violência contra a mulher transcende contextos históricos e tem fortes laços com a ordem patriarcal na sociedade, sendo tratada por vezes com pouca consideração. É importante ressaltar que fatores como condições financeiras, medo e baixa escolaridade contribuem para a manutenção da mulher em relacionamentos abusivos.

No que tange à escolaridade, identificou-se que a maioria das vítimas apresentava menos de 8 anos de estudo. Em pesquisa ${ }^{(8)}$ realizada no Rio Grande do Sul, verificou-se que os casos mais frequentes acometeram mulheres com ensino fundamental incompleto $(33,5 \%)$. Sabe-se que a fragilidade educacional está diretamente relacionada ao desconhecimento da mulher sobre os seus direitos.

Neste contexto, a Lei Maria da Penha representa importante conquista e um recurso imprescindível para o enfrentamento da violência contra a mulher, e é reconhecida pela Organização das Nações Unidas (ONU) como uma das três melhores legislações para o combate a esse tipo de violência ${ }^{(9)}$.

Atualmente, a violência de gênero continua presente em muitas culturas. Segundo a OMS, uma em cada três mulheres no mundo irá vivenciar a violência física ou sexual perpetrada por parceiro íntimo durante a vida(8).

Os altos índices da violência podem ser explicados pela carência de conhecimento histórico do fenômeno da violência e despreparo dos profissionais atuantes nessa área, seja pela cultura machista presente na sociedade ou pelo fato de as próprias mulheres não conseguirem compreender as razões que levam os homens que elas amam a lhes agredir, tornando mais difícil a decisão de denunciar seus parceiros ${ }^{(10)}$.

Ressalta-se que baixos graus de instrução estão relacionados ao aumento da incidência de casos de violência. Em contrapartida, vítimas com maior escolaridade e poder aquisitivo tendem a buscar serviços de saúde privados e podem solicitar a omissão da informação, mesmo este sendo uma obrigatoriedade de todos os prestadores de saúde, gerando subnotificações e distorção do real perfil de violência.

No que diz respeito à idade da vítima, observou-se predomínio de adultos. Resultados semelhantes foram encontrados em estudo (11) que apontou $51,0 \%$ dos casos representados por adultos com a mesma faixa etária. Embora esta população seja mais acometida, salienta-se que atos de violência também são constatados em grupos vulneráveis, como crianças, adolescentes e idosos. Crianças e adolescentes podem ser considerados grupos vulneráveis e apresentam uma dificuldade maior em externar a violência por eles sofrida, em virtude de que, geralmente, o agressor é alguém da própria família(12).

Informações obtidas nesta pesquisa demonstraram que indivíduos de raça branca foram os mais acometidos. O elevado índice de raça branca associa-se à colonização da região sudoeste do Estado por imigrantes gaúchos e catarinenses a partir de 1940(13).

No que se refere à situação conjugal e orientação sexual, houve predomínio de 
vítimas com companheiro e heterossexuais. Essa informação leva a crer que a maioria dos casos pode estar relacionada à violência doméstica contra a mulher, na qual existe possivelmente relação estável, e o agressor é seu próprio companheiro.

Considerando o local de ocorrência, na presente pesquisa houve destaque para a residência (71,3\%) seguido de via pública $(10,3 \%)$, divergindo de estudo(14) realizado nos serviços de urgência e emergência das capitais brasileiras no âmbito do SUS, no qual $42,5 \%$ dos casos ocorreram em via pública, e 33,0\% na residência. A residência deveria ser um espaço de segurança e proteção, principalmente no âmbito infantil, porém é o lugar onde a violência tem apresentado maior destaque ${ }^{(15)}$.

No Brasil, os agravos ocasionados pelas causas externas correspondem à terceira causa de morte da população geral(4). O Atlas da Violência ${ }^{(16)}$ revela que, nos últimos dez anos, 553 mil indivíduos perderam a vida devido à violência intencional no país.

Pode-se justificar que o crescente número de notificações está associado à representatividade da violência nos dias atuais por meio da mídia, redes sociais, elaboração de leis e visibilidade de casos, cada vez mais presentes no nosso cotidiano, levando a uma maior discussão e ao empoderamento das pessoas sobre o assunto.

Em relação à fonte notificadora, houve destaque para a unidade de saúde $(99,6 \%)$, assemelhando-se a estudo ${ }^{(15)}$ que buscou analisar os índices de violência infantil em Ribeirão Preto-SP, no qual 79,3\% das notificações eram provenientes deste mesmo local. Sugere-se que a vítima procure os serviços de saúde devido a problemas causados pela violềncia e, portanto, cabe aos profissionais de unidades de saúde, hospitais ou pronto atendimento o adequado acolhimento da vítima e a realização da notificação.

Referente ao número de violências sofridas pela vítima, a presente pesquisa revelou que $55,5 \%$ sofreram um tipo e $31,3 \%$ dois tipos de violência, simultaneamente. Entendese que, quando um indivíduo sofre uma agressão, geralmente existe mais de um tipo de violência ocorrendo, física e psicológica, por exemplo, tornando difícil identificá-las isoladamente. Nesse contexto, supõe-se que algumas vítimas tenham sofrido mais de uma violência, contudo não a identificaram de forma dissociada da física.

No que concerne ao sexo do autor da violência, a pesquisa traz notoriedade para o masculino (75,5\%), dado que se assemelha a estudo(17) realizado em Belém-PA, no qual o homem prevaleceu $(90,5 \%)$ como autor.

Observa-se também que o agressor se encontrava na faixa etária adulta $(51,3 \%)$ e que o número de envolvidos no caso da violência foi um agressor, com $72,5 \%$, fato que pode estar associado ao cônjuge, sendo o maior agressor neste estudo.

Ao longo da história, os homens foram vistos como seres dominadores, com direito de controlar suas mulheres e se necessário, utilizar a violência como meio de demonstrar poder. Essa atitude até então era vista como algo cultural e de certa forma, natural(12). Atualmente, estudos mostram que o homem ainda tende a usar a violência com o intuito de intimidar e expressar autoridade ${ }^{(9)}$.

No tocante ao tipo de violência, observou-se nesta pesquisa que a violência física destacou-se $(74,8 \%)$, corroborando estudo(14) no qual $87,8 \%$ das notificações foram de agressão física. Esse tipo de violência é definida como qualquer ação que fere a integridade física ou saúde corporal do indivíduo, podendo atingir qualquer pessoa e faixa etária É também a que pode ser percebida mais facilmente, diferente de outras violências como a psicológica, que não deixa marcas visíveis, passando despercebida na maioria das vezes, contribuindo para a subnotificação(14).

Quanto ao meio de agressão, na atual pesquisa destacou-se força corporal seguida de ameaça, discordando de pesquisa ${ }^{(17)}$ realizada em 2013, na qual destacaram-se ameaça $(59,7 \%)$ e espancamento $(27,4 \%)$. 
O uso da força e a ameaça são formas de violência e caracterizam a dominância e o controle do agressor sobre as vítimas. Nesse contexto, é importante destacar que as vítimas, muitas vezes, não verbalizam as agressões sofridas, por medo ou por sentirem-se intimidadas pelo agressor.

Tendo em consideração a suspeita do uso de álcool pelo agressor, na presente pesquisa $39,4 \%$ haviam consumido bebida alcóolica. Em relação ao vínculo com o provável autor da violência, houve destaque para o cônjuge, ao passo que $44,8 \%$ das agressões ocorreram outras vezes, dados que se assemelham a estudo ${ }^{(11)}$ no qual $32,2 \%$ dos agressores tinham suspeita de uso de bebida alcóolica e vínculo com a vítima, e em que o cônjuge representou $27,5 \%$ das notificações.

O consumo de álcool é um fator de risco, pois contribui para a ocorrência de atos violentos. Em vista disso, o alcoolismo pode ser considerado um desinibidor, tornando o agressor mais corajoso e inconsequente ${ }^{(18)}$.

No que tange à profilaxia utilizada em casos de violência sexual, houve predomínio da profilaxia para o Vírus da Imunodeficiência Humana (HIV) e para outras Infecções Sexualmente Transmissíveis (IST). Neste sentido, vale ressaltar a importância do conhecimento dos protocolos de profilaxia por parte dos profissionais de saúde e das instituições de referência para o atendimento de casos de violência, com o intuito de minimizar os riscos de exposição das vítimas.

De acordo com o Protocolo Paranaense para o Atendimento às Pessoas em Situação de Violência Sexual, a profilaxia pós-exposição irá contemplar as IST mais prevalentes e está indicada em situações com risco de transmissão de sífilis, gonorreia, clamídia, tricomoníase, hepatite $\mathrm{B}$ e $\mathrm{HIV}^{(19)}$.

A violência sexual pode ocorrer independentemente da idade ou sexo da vítima, acarretando inúmeros prejuízos psicossociais, além do risco de contrair Infecções Sexualmente Transmissíveis como HIV e hepatites virais. A frequência real desse ato ainda não é conhecida, visto que as vítimas tendem a não informá-la, em virtude do receio, desconhecimento de leis que a amparam e da vergonha. Por isso, o tratamento pósviolência sexual é considerado uma prioridade quando se trata de assistência à saúde. Esse direito é garantido pela Lei $n^{\circ} 12.845 / 2013$, determinando que o atendimento de pessoas em situação de violência sexual seja obrigatório e integral(20).

Quanto às limitações do estudo, apesar do alto índice de casos notificados, chama a atenção as possíveis omissões dos serviços de saúde, a falta de empoderamento feminino no cenário atual, bem como a presença de informações reportadas como "ignorado ou não se aplica" pelos profissionais da saúde.

\section{CONCLUSÃO}

A violência é um fenômeno democrático, enraizado na sociedade e permeado em diversas culturas, e por ser também considerada um problema de saúde pública mundial, é importante compreendê-la para o enfrentamento e elaboração de estratégias de prevenção e controle.

Há de se considerar ainda que o treinamento dos profissionais responsáveis pelo preenchimento das fichas de notificação é de grande importância para que o realizem de forma correta, propiciando dados condizentes com a realidade deste agravo. Ademais, que estes estejam devidamente preparados para acolher as vítimas, proporcionando uma relação de confiança, favorecendo a elaboração de intervenções mais efetivas no combate à violência.

Neste contexto, faz-se necessária a implementação de políticas públicas e a efetivação 
de programas de combate à violência, que não se atenham apenas às implicações legais dos agressores, mas que sejam fomentadoras de novos subsídios, contribuindo, assim, para a redução das taxas de morbimortalidade e maior sensibilização da população em geral.

A pesquisa confirma a relevância da notificação dos casos e de uma prática assistencial à saúde baseada nos preceitos de responsabilidade profissional. Portanto, conhecer as características dos casos de violência da regional estudada contribui para um melhor entendimento acerca do tema, bem como novos estudos que abordem esta temática.

\section{REFERÊNCIAS}

1. World Health Organization (OMS). Preventing violence and reducing its impact: How development agencies can help. France. [Internet] 2008. [acesso em 22 ago 2019]. Disponível em: http://whqlibdoc. who.int/publications/2008/9789241596589 eng.pdf.

2. Bozzo $A C B$, Matos $G C$, Berald LP, Souza MD de. Violência doméstica contra a mulher: caracterização dos casos notificados em um município do interior paulista. Rev. enferm. UERJ. [Internet]. 2017 [acesso em 12 mar 2018]; 25. Disponível em: http://dx.doi.org/10.12957/reuerj.2017.11173.

3. Martins A de C, Fernandes CR. Mortalidade por agressões e lesões autoprovocadas voluntariamente: reflexões sobre a realidade brasileira. Saúde foco. [Internet]. 2014 [acesso em 05 fev 2018]; 1(1).

Disponível em: https://smsrio.org/revista/index.php/revsf/article/view/163/177.

4. Ministério da Saúde (BR). Secretaria de Vigilância em Saúde. Departamento de Vigilância de Doenças e Agravos Não Transmissíveis e promoção da Saúde. Viva: Instrutivo. Notificação de violência interpessoal e autoprovocada. [Internet]. Brasília: Ministério da Saúde; 2016 [acesso em 08 fev 2018]. Disponível em: http://bvsms.saude.gov.br/bvs/publicacoes/viva instrutivo violencia interpessoal autoprovocada 2ed. pdf.

5. Brasil. Portaria n. 1.271, de 6 de Junho de 2014. Define a Lista Nacional de Notificação Compulsória de doenças, agravos e eventos de saúde pública nos serviços de saúde públicos e privados em todo o território nacional, nos termos do anexo, e dá outras providências. [Internet]. Diário Oficial da União. 2014 [acesso em 22 ago 2019]. Disponível em: http://www.saude.pr.gov.br/arquivos/File/ PORTARIA1271de06 062014 LISTANACDENOTIFCOMPULSoRIA.pdf.

6. Instituto Brasileiro de Geografia e Estatística (IBGE). Contagem Populacional 2018. [Internet]. 2018 [acesso em 17 out 2018]. Disponível em: https://cidades.ibge.gov.br/brasil/pr/francisco-beltrao/ panorama.

7. Secretaria de Estado da Saúde do Paraná (PR). Superintendência de Atenção à Saúde. Protocolo para o atendimento às pessoas em situação de violência sexual. [Internet]. SESA; 2017 [acesso em 13 out 2018]. Disponível em: http://www.saude.pr.gov.br/arquivos/File/Protocolo para o Atendimento as Pessoas em_Situacao de Violencia_Sexual_09012018ultimaversao.pdf.

8. Lawrenz P, Macedo DM, Hohendorff J Von, Freitas CPP de, Foschiera LN, Habigzang LF. Violência contra mulher: notificações dos profissionais da saúde no Rio Grande do Sul. Psic.: Teor. e Pesq. [Internet]. 2018 [acesso em 27 jun 2019]; 34(e34428). Disponível em: http://www.scielo.br/pdf/ptp/v34/ pt 1806-3446-ptp-34-e34428.pdf.

9. Garcia LP, Silva GDM da. Violência por parceiro íntimo: perfil dos atendimentos em serviços de urgência e emergência nas capitais dos estados brasileiros, 2014. Cad. saúde pública. [Internet]. 2018 [acesso em 18 set 2018]; 34(4). Disponível em: http://dx.doi.org/10.1590/0102-311x00062317.

10. Elias MLG, Machado IV. A Construção social da liberdade e a lei Maria da Penha. Rev. sul-americana de ciência política. [Internet]. 2015 [acesso em 25 set 2018]; 3(1). Disponível em: https://periodicos.ufpel. edu.br/ojs2/index.php/rsulacp/article/view/3865. 
11 Sinimbu RB, Mascarenhas MDM, Silva MMA da, Carvalho MGO de, Santos MR dos, Freitas MG. Caracterização das vítimas de violência doméstica, sexual e/ ou outras violências no Brasil - 2014. Saúde foco. [Internet]. 2016 [acesso em 05 fev 2018]; 1(1). Disponível em: https://smsrio.org/revista/index.php/ revsf/article/view/199/178.

12. Silva PA, Lunardi VL, Lunardi GL, Arejano CB, Ximenes AS, Ribeiro JP. Violencia contra niños y adolescentes: características de los casos reportados en un Centro de Referencia del Sur de Brasil. Enfermería global. [Internet]. 2017 [acesso em 18 abr 2018]; 16(2). Disponível em: http://dx.doi. org/10.6018/eglobal.16.2.235251.

13. Almeida ACS. A Colonização do território paranaense e o dinamismo dos municípios da frente norte. Ver. GEOMAE [Internet]. 2016 [acesso em 24 ago 2019]; 7(1). Disponível em: http://www.fecilcam.br/ revista/index.php/geomae/article/viewFile/273/pdf 190.

14. Souto RMCV, Barufaldi LA, Nico LS, Freitas MG de. Perfil epidemiológico do atendimento por violência nos serviços públicos de urgência e emergência em capitais brasileiras, Viva 2014. Ciênc. saúde coletiva. [Internet]. 2017 [acesso em 03 mar 2018]; 22(9). Disponível em: http://dx.doi.org/10.1590/141381232017229.13342017.

15. Farias MS, Souza C da S, Carneseca EC, Passos ADC, Vieira EM. Caracterização das notificações de violência em crianças no município de Ribeirão Preto, São Paulo, no período de 2006-2008. Epidemiol. Serv. Saúde. [Internet]. 2016 [acesso em 03 mar 2018]; 25(4). Disponível em: http://www.scielo.br/pdf/ ress/v25n4/2237-9622-ress-25-04-00799.pdf.

16. Cerqueira D, Lima RS de, Bueno S, Neme C, Ferreira H, Coelho D, et al. Atlas da Violência. Ipea. In: Fórum Brasileiro de Segurança Pública. [Internet]. 2018 [acesso em 13 out 2018]. Disponível em: http:// www.ipea.gov.br/portal/index.php?option=com content\&view=article\&id=33410\&ltemid=432.

17. Veloso MMX, Magalhães CMC, Dell'Aglio DD, Cabral IR, Gomes MM. Notificação da violência como estratégia de vigilância em saúde: perfil de uma metrópole do Brasil. Ciênc. saúde coletiva. [Internet]. 2013 [acesso em 18 set 2018]; 18(5). Disponível em: http://www.scielo.br/pdf/csc/v18n5/11.pdf.

18. Ferreira TB, Lopes AOS. Alcoolismo, um caminho para a violência na conjugalidade. Rev. UNIABEU. [Internet]. 2017 [acesso em 07 out 2018]; 10(24). Disponível em: http://revista.uniabeu.edu.br/index.php/ RU/article/view/2527.

19. Secretaria de Estado da Saúde (PR). Superintendência de Atenção à Saúde. Protocolo Paranaense para o Atendimento às Pessoas em Situação de Violência Sexual. [Internet]. Curitiba: Secretaria de Estado da Saúde; 2018 [acesso em 18 out 2019]. Disponível em: http://www.saude.pr.gov.br/arquivos/File/ Protocolo para o Atendimento as Pessoas em Situacao de Violencia Sexual 09012018ultimaversao. pdf.

20. Ministério da Saúde (BR). Secretaria de Vigilância em Saúde. Departamento de DST, Aids e Hepatites Virais. Protocolo Clínico e Diretrizes Terapêuticas para Atenção Integral às Pessoas com Infecções Sexualmente Transmissíveis. [Internet]. Brasília: Ministério da Saúde; 2015 [acesso em 13 out 2018]. Disponível em: http://www.aids.gov.br/pt-br/pub/2015/protocolo-clinico-e-diretrizes-terapeuticas-paraatencao-integral-pessoas-com-infeccoes.

Recebido: 06/12/2018

Finalizado: 08/04/2020

Editora associada: Susanne Elero Betiolli 
Av. Júlio Assis Cavalheiro, 2000 - 85601-000 - Francisco Beltrão, PR, Brasil

E-mail: lediana@prof.unipar.br

Contribuição dos autores:

Contribuições substanciais para a concepção ou desenho do estudo; ou a aquisição, análise ou interpretação de dados do estudo - MR

Elaboração e revisão crítica do conteúdo intelectual do estudo - GTT, TBF, MDT, EC

Aprovação da versão final do estudo a ser publicado - LDC

Responsável por todos os aspectos do estudo, assegurando as questões de precisão ou integridade de qualquer parte do estudo - CMA, LDC 